\title{
SEMBLANZA
}

\section{Dr. Guillermo Adriasola \\ Uno de los "Grandes" de la Salud Pública}

\author{
DANIELA ARANEDA(1), SYLVIA PESSOA(1)
}

A los 97 años, y dejando su huella marcada en el camino por donde han pasado los grandes hombres y mujeres de la salud pública, se marchó el Dr. Guillermo Adriasola Espejo. Quien fuera director de la Escuela de Salud Pública entre los años 1964 y 1968, no sólo fue conocido por su espíritu colaborador y solidario, sino también por su inteligencia, su capacidad para adelantarse a los hechos y por haber sabido conjugar la pediatría con la visión colectiva de la salud materno - infantil.

Recién titulado, inició su carrera en Punta Arenas, ciudad que lo distinguió como hijo ilustre. Allí, en la postergada región austral del país, se convirtió en pionero de la medicina pública, dedicando tiempo y esfuerzo a ayudar a la comunidad. Ingresó al Cuerpo de Bomberos local y luego formó parte de la aviación civil, alcanzando el grado de subteniente de reserva. 24 horas flotando en el mar tras un accidente aéreo, familias en el aislamiento casi total, un clima inmisericorde y muchos sacrificios fueron parte de las vivencias en su autoimpuesta misión de llevar ayuda médica a los rincones más australes de Chile.

Por sus convicciones y condiciones, que lo destacaron siempre como hombre de servicio, durante el gobierno de Juan Antonio Ríos fue nombrado Intendente de la Provincia de Magallanes, cargo que desempeñó entre los años 1941 y 1946.

\section{LA ESCUELA Y LAS FAMILIAS}

En el año 1948 ingresó a la Escuela de Salubridad de la Universidad de Chile, donde fue un alumno destacado, lo que le significó ser enviado en 1949 a la Universidad de Harvard. A su regreso, al año siguiente, fue nombrado Profesor Titular de la cátedra de Higiene Materno - Infantil y comenzó a trabajar con el Dr. Gustavo Molina.

En 1964 asumió la dirección de la Escuela, cargo que desempeñó hasta 1968. En esta institución entregó su visión amplia y profunda de la salud pública, especialmente en los ámbitos de la administración y de la salud materno infantil.

Durante su gestión, se creó una unidad de estudios formada por un grupo multidisciplinario de profesionales que realizó una importante labor. Investigaciones sobre gasto en salud, una inédita encuesta sobre determinantes socioculturales de la demanda de atención en salud -que abarcó cuatro mil familias y que por primera vez incluyó la ruralidad- $y$ un estudio de la mortalidad infantil en América Latina, fueron sólo algunos de sus legados.

En lo humano, quienes lo conocieron lo recuerdan como una persona que le daba tiempo a todo y a todos y generaba espacios para que la gente surgiera, generara ideas y se desarrollara. Muy respetuoso del trabajo en equipo y de todos quienes integraban la Escuela, fue además un hombre que gustaba de hacer medicina en terreno, un trabajador incansable y un visionario innato ante los problemas, las consecuencias y las soluciones.

Entre 1973 y 1975 estuvo en el Departamento de Fomento a la Salud en el ministerio del ramo, cargo que dejó en 1975

(1) Escuela de Salud Pública, Universidad de Chile. daraneda@med.uchile.cl 
para asumir el Decanato de la Facultad de Medicina de la Universidad de Chile hasta 1980.

$\mathrm{Su}$ permanente inquietud por aportar al bienestar y a la salud integral de las personas lo llevó en 1974 a presidir la Asociación de Protección a la Familia (Aprofa) durante una década. Pero eso parecía no ser suficiente para el Dr. Adriasola; se embarcó entonces en la creación de la Corporación Nacional de Orientación Familiar (Conorfa).

Desde allí pudo actuar y llevar programas específicos a las familias en riesgo social, a través de programas de fomento, prevención y educación en temas como drogadicción, violencia intra familiar y adolescencia. En este trabajo voluntario contó con la colaboración de alumnos de la Escuela de Medicina y de colegas como Cristian Prado, Juan Francisco Labra, Francisco Mardones y Sergio González. Estos programas, iniciados en las poblaciones marginales de Lo Barnechea y Lo Hermida, están aún en vigencia y se sustentan gracias a la buena voluntad de quienes heredaron del Dr. Guillermo Adriasola una de sus grandes cualidades: su preocupación e interés por la salud de los más desposeídos. 